\title{
Proposed energy management for a decentralized DC-microgrid based PV-WT-HESS for an isolated community
}

\author{
Hafsi Oussama ${ }^{1}$, Abdelkhalek Othmane ${ }^{2}$, Hartani Mohammed Amine ${ }^{3}$, Chakar Abdeselem ${ }^{4}$, \\ Soumeur Mohammed Amine ${ }^{5}$ \\ 1,2,3,4,5 Smart Grids and Renewable Energies Laboratory SGRE, University of Tahri Mohamed, Bechar, Algeria \\ ${ }^{3}$ Laboratory of durable development and informatics LDDI, University of Ahmed Draia, Adrar, Algeria
}

\section{Article Info}

Article history:

Received Jan 21, 2020

Revised Apr 26, 2020

Accepted Jun 10, 2020

\section{Keywords:}

Control and management

DC microgrid

DC/DC converter

Energy storage system

Renewable energies

\begin{abstract}
Microgrids are small-scale power systems destined to supply isolated villages and optimum utilization of renewable energies. For this reason, this paper presents a DC-MG of $150 \mathrm{Kwp}$ to feed an island village. The configuration of the proposed system consists of four interconnected sub-sections supplied by the centralized unit through PV and Wind Distributed Energy Resources DERs, in addition to the supercapacitor storage device. In the other hand, internal batteries of each sub-section cover its load demand separately, where electrical and chemical storage devices can be advantageous hybrid energy storage system HESS for the system. Thus, the control structure of the DCMG is based on current hysteresis method to assure the charge/discharge operation and the stability of the DC-bus voltage, then a proposed management strategy to manage the shared energy of the DCMG system. The system behavior is tested under variable parameters and conditions using Matlab/Simulink
\end{abstract}

This is an open access article under the CC BY-SA license.

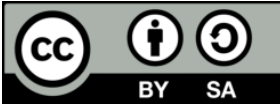

\section{Corresponding Author:}

Hafsi Oussama,

Smart Grids \&Renewable Energies Laboratory SGRE-L, Department of Electrical Engineering,

University of Tahri Mohamed, Bechar, Algeria

The independence street, PB 417 Bechar Algeria,

Email: hafsi.oussama@pg.univ-bechar.dz,oussama5bm@gmail.com

\section{INTRODUCTION}

In the last years, there is a quick increase of clean and sustainable energy-based renewable energy sources REs in power systems [1]. To make the best utilization of renewable energy, Microgrids have been widely studied and have an important role in the future energy [2], to decrease the consummation of fossil energy and to create a solution for remote areas. A Microgrid system integrates several types of REs to feed the household and industrial load. It can be classified to AC and/or DC Microgrid. DC-MG combines various REs such as photovoltaic PV, wind turbine WT, Fuel cell FC and biomass, in addition to storage devices such as chemical batteries, electrical supercapacitor SC and flywheel, and DC loads [3]. DC-MG systems present more advantages compared to traditional AC-MG, where we neglect alternative parameters and disturbances [2]. In literature, DC-MG is more advantageous compared with AC-MG in term of the initial cost, the net saving value, the payback period and the system efficiency [4].

In recent years, researchers are going toward DC-MG field, especially with increasing its applications in EV, data and telecommunication centers, residential cities ... etc. [5]. Hence, the use of renewable and non-renewable DERs results in many types of MGs, which varies from simple to complicated configurations following the used topology and the voltage/power level of the system. In [6], the authors have proposed PV/Battery DC-MG, PV/WT/Battery topology in [7], while [8] studies a DC-MG based 
PV/WT/FC/Battery. Other researcher dealt with EV in FC/Battery/SC topology [9]. In DC-MG, suitable topology depends on the needed application and region condition. Besides, we distinguish two operation modes, Grid-off mode when the DC-MG operates autonomously and separately from the main grid. In the other side, the MG operates in parallel with the grid in Grid-Tied mode, where the mismatched/exceeded energy is supplied/absorbed by the grid side respectively [10].

This paper presents simulation, control and management of the proposed decentralized DC-MG based PV/WT/HESS under specified load schedule and variable sun potential of the studied zone. The goal of this study is to ensure the following:

- Uninterruptable operation of the whole system during normal, critical and emergency cases.

- Control the charge/discharge cycles of the HESS devices based on its energy/power densities.

- Manage the shared energy/power inside the DC-MG under a stable DC bus voltage

The proposed DC-MG shown in Figure 1 consists of PV and WT as DERs, supercapacitor and 4 sub-sections, each sub-section has local batteries and loads.

In this study, we used Semi-active topology where the supercapacitor is connected directly to DCbus, while Bidirectional converters BDC control the functioning of the local batteries $[11,12]$.

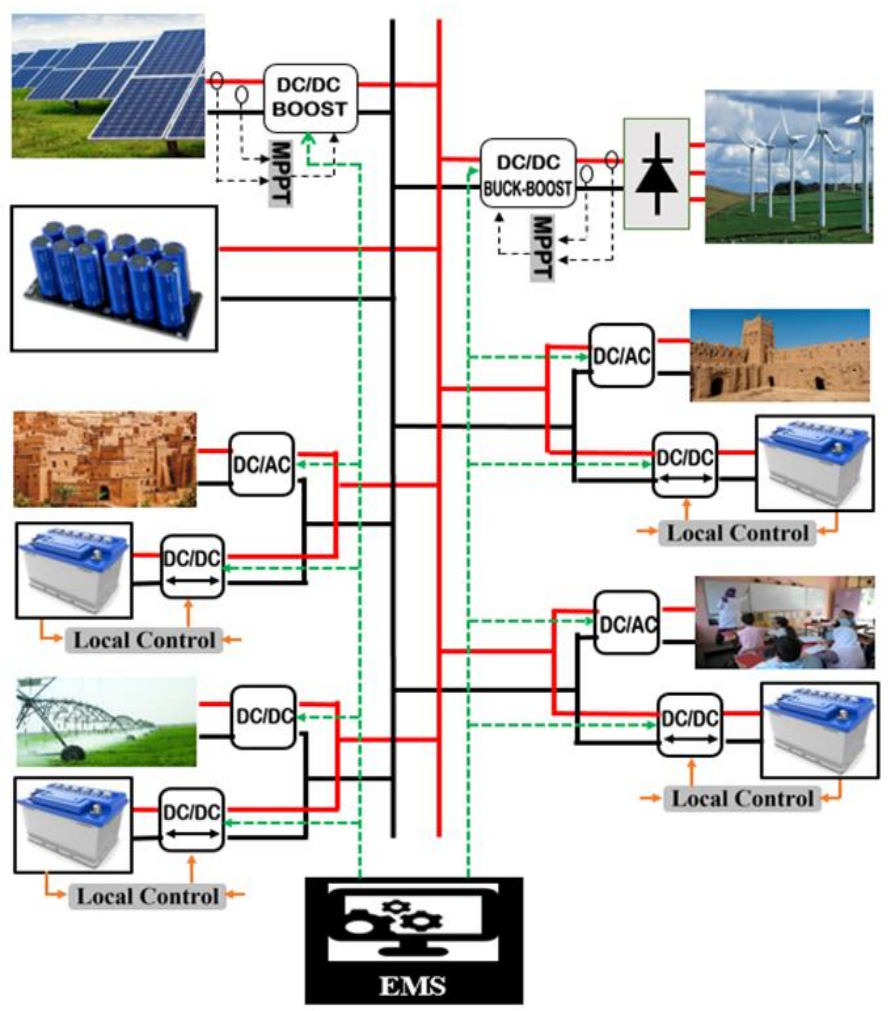

Figure 1. Proposed structure of the studied DC-MG

\section{MODELING OF THE DC-MG}

In the proposed DC-MG, PV is considered as the principal source and WT is the secondary, while the HESS aims to ensure the power balance and the stability of the system. This order is based on the availability of the DERs, and especially the amount of the delivered energy of each DER. The sizing of the system DERs is not considered in this article.

\subsection{PV panel}

The PV source can be represented by an equivalent ideal current source connected with series and parallel resistors, in addition to a pay bass diode. Equation (1) describes the output current of the PV: [5, 13].

$$
I_{p v}=\left(I_{p v, N}+K_{I} \cdot \Delta_{T}\right) \cdot \frac{G}{G_{n}}
$$


Where IPV is the array current (A), IPV, N is the STC (Standard Test Condition) value of IPV, KI is the short circuit current temperature coefficient, $\Delta_{-} \mathrm{T}$ is the difference between actual and nominal temperature, $\mathrm{G}$ is the actual sun irradiation $\left(\mathrm{W} / \mathrm{m}^{2}\right)$ and $\overline{\mathrm{G} n}$ is the STC value of the sun irradiation.

\subsection{Wind turbine generator and PMSG}

The wind turbine is used for the conversion of kinetic energy, there are many of generators to transfer the mechanical power to electrical power, PMSGs are becoming increasingly popular for wind power applications $[14,3]$, it can generate the electrical power in variable wind speed.The topology that used in this study is "PMSG direct-driven" with non-controlled rectifier, associated with a DC/DC converter. The mechanical power obtained by rotor blades is:

$$
P_{m}=\frac{1}{2} \rho \pi \mathrm{R}^{2} \mathrm{~V}^{3} \mathrm{C}_{\mathrm{P}}(\beta, \lambda)
$$

Where, $\rho$ is the air density $(\mathrm{kg} / \mathrm{m} 3), \mathrm{R}$ is the radius of wind turbine blade $(\mathrm{m}), \mathrm{V}$ is wind speed $(\mathrm{m} / \mathrm{s})$ and $(\lambda, \beta)$ is the power coefficient, which expresses the relationship between the tip speed ratio $\lambda$ and the pitch angle $\beta$.

\subsection{Battery}

The battery in this work is a Lead-acid type because of its wide advantages such as low cost and high rate of recycling $97 \%[5,15]$. The output voltage of the battery is

$$
U_{b}=E-R_{b} i_{b}=\mathrm{E} E_{0}-K \frac{Q}{Q-i t} * i t+A_{b} \exp (-B * i t)-P o l_{r e s} * i^{*}-R_{b} i_{b}
$$

Where $\mathrm{U} \_\mathrm{b}$ is the battery output voltage, E is open-circuit voltage, E0 is the battery internal equivalent voltage, $\mathrm{K}$ is polarization constant, $\mathrm{Q}$ is the maximum battery capacity, it is the extracted capacity, $\mathrm{Rb}$ is internal impedance, $\mathrm{ib}$ is the battery current, and $\mathrm{i}^{*}$ is the filtered battery current. Polres is polarization resistance.

\subsection{Supercapacitor SC}

The SC can release or absorb high current spikes during a short time in milliseconds due to its high power density [16], in addition to its high-efficiency cycle about (100\%) and more charge/discharge cycle compared to the chemical batteries [17]. In [18], detailed modelling of the supercapacitor is deliberated. The SC energy ESC is described by its voltage VSC and capacitance CSC [16]:

$$
E_{S C}=\frac{C_{S C} V_{S C}^{2}}{2}
$$

\subsection{Electronic power converters}

In our DCMG, DC/DC converters are represented by switching models, where pulse with modulation PWM schemas are implemented considering losses and harmonics. This mode requires high switching frequency that make the simulation more time consuming.

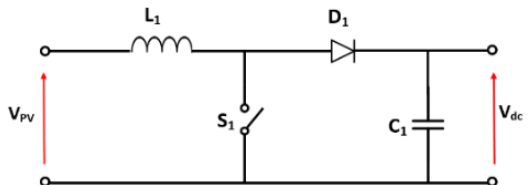

(a)

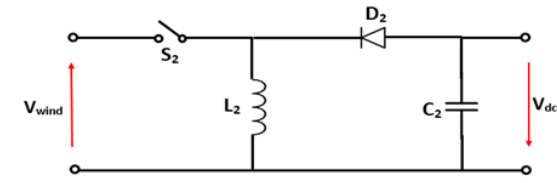

(b)

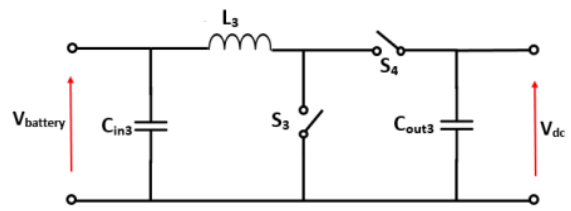

(c)

Figure 2. Circuits of the DC/DC power converters: (a) Boost, (b) Buck-Boost, (c) BDC 


\subsubsection{Boost converter}

Boost converter is a non-isolated DC-DC converter able to boost the output voltage greater than the input, it is also known as step up converter [19] as shown in figure (2-a). The boost converter has two operation periods. During first period, the controlled switch S1 is ON, while S1 is turned OFF in the second period [14]. The duty cycle formulation of the boost converter is:

$$
D=1-\frac{V_{I N}}{V_{\text {OUT }}}
$$

\subsubsection{Buck boost converter}

DC/DC Buck-boost converter shown in figure (2-b) is able to generate an inverted output voltage greater than or less than the input voltage, where it operates in the buck mode when $\mathrm{k}<0.5$ and in the boost mode when $\mathrm{k}>0.5$ [14]. The duty cycle can be find by

$$
D=\frac{V_{\text {OUT }}}{V_{\text {OUT }}+V_{I N}}
$$

\subsubsection{Bidirectional buck-boost converter BDC}

$\mathrm{BDC}$ is an electronic interface between the DC-bus and the battery, which assure the charge/discharge operation. The BDC has two modes, boost mode when the battery discharge (S3: ON \& S4: OFF), and buck when the battery charge (S3: OFF \& S4: ON). The two switches of the BDC are controlled complimentary via the PWM signal commands of the cascade-closed loop (voltage \& current hysteresis) [20].

\subsection{Loads}

The proposed system supplies both DC and AC loads, where AC type consists of tow 02 housing with $50 \mathrm{Kwp}$ for each, a polyclinic and primary school of $22 \mathrm{Kwp}$. The fourth DC load of $28 \mathrm{Kwp}$ is destined for an agriculture applications.

\section{CONTROL AND ENERGY MANAGEMENT STRATIGY}

The management system policy MSP aims to provide the load side with uninterruptable energy in addition to protect the system components [21]. The global control structure consists of two topologies, which are:

1- $\quad$ MPPT controller of the conversion chains of PV/WT sources.

2- $\quad$ Closed control loops of the DC/DC BDC of local batteries.

The control strategy of the decentralized configuration aims to manage the shared energy inside and between the interconnected sections separately through their local controllers LC of the BDC of batteries.

\subsection{Control structure of the PV conversion chain:}

In this part, the PV is controlled during sunny hours by the MPPT controller to extract its maximum power using conventional $\mathrm{P} \& \mathrm{O}$ method with PI regulator to maintain the bus voltage.

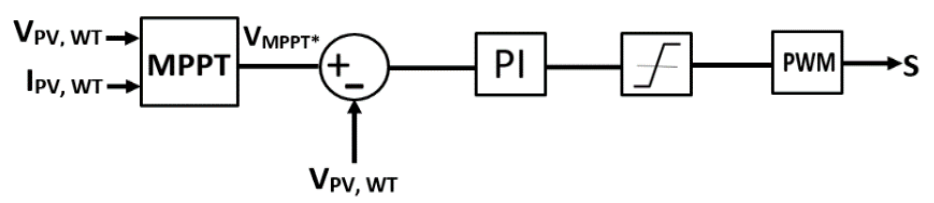

Figure 3. Common control structure of PV/WT sources based MPPT.

The operation principle of this method is to adjust the operating voltage in terms of power until achieving the relationship $\mathrm{dP} / \mathrm{dV}=0[22,23]$.

\subsection{Control structure of the WT conversion chain}

The proposed control method requires only power output measurement of the conversion chain of WT. This can be achieved from the DC link's current and voltage without requiring any speed or wind 
measurements or another mechanic factor [24, 25]. Maximum power operation for a WT realized when the ratio of the power variation on the speed variation equal to zero. In addition, the back-emf of a PMSG is proportional to the rotational speed $\omega$, and hence it can be shown that $[24$

$$
\frac{d P}{d V_{d c}}=0
$$

Using the deference power $\mathrm{dP}$ and creasing or decreasing the DC-bus voltage can be achieve the MPP at practical speed rotational. by utilization P\&O or Hill-Climbing Search HCS [25] to extract the MPP from available wind speed and to give the Vdc reference as shown in figure 3 to PI controller to regulate the output power at $400 \mathrm{~V}$.

\subsection{Buck-boost bidirectional converter control}

The control structure shown in figure 6 describes the operation principle of the charge/discharge of the battery. The cascade topology aims to mitigate the bus voltage variations by the PI regulator and then generates the reference current to the hysteresis regulator, either to charge or discharge cases.

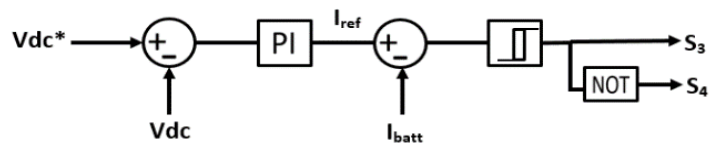

Figure 4. Control structure of the BDC of the local batteries.

\subsection{Management strategy}

The following flowchart describes the energy management strategy of the DCMG, which aims to control and protect the system parts, where four modes are used to supervise the DERs operation, control the charge/discharge of the local batteries and assure the load demand. Table 1 illustrate the selected modes.

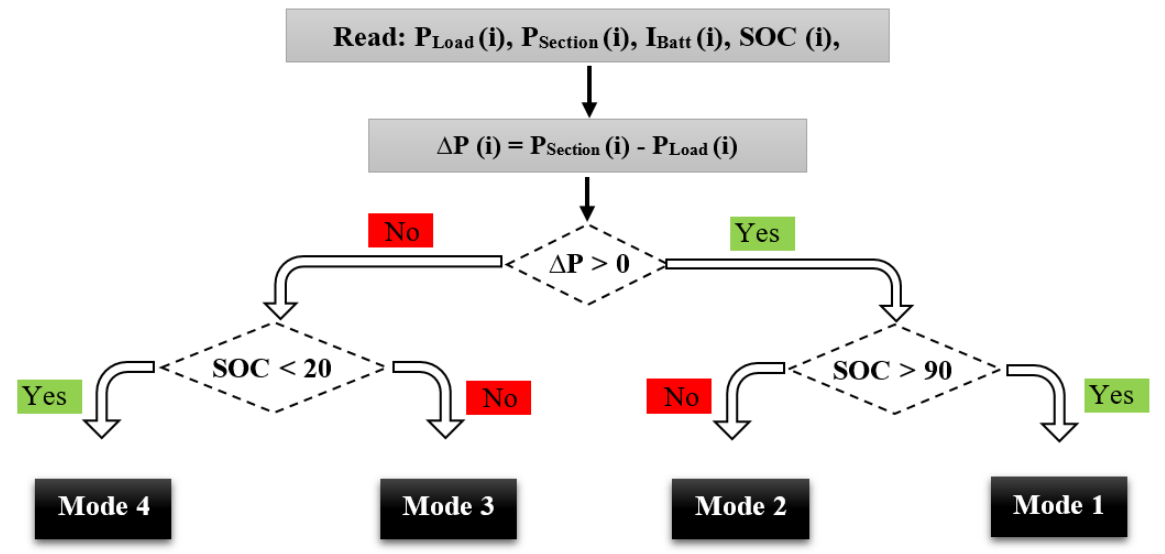

Figure 5. Flowchart of the power management policy of DC-MG.

Table 1. Explanation of the management modes.

\begin{tabular}{|c|c|}
\hline Modes & Description \\
\hline Mode 1 & $\begin{array}{l}\text { In this mode, the selected battery is turned OFF and the load supplied via renewable sources, the EMS give an order } \\
\text { to renewable sources to change the control mode from MPPT to droop control mode. }\end{array}$ \\
\hline Mode 2 & $\begin{array}{l}\text { In this case, the generated power more than the demand power and the SOC of the battery between } 90 \% \text { and } 20 \% \text {, so } \\
\text { the associated battery is charging. }\end{array}$ \\
\hline Mode 3 & $\begin{array}{l}\text { The demand power more than the injected power at the DC-bus from renewable sources and the SOC of charge of the } \\
\text { associated battery more than } 20 \% \text {, so here the battery is discharging to cover the missing power. }\end{array}$ \\
\hline Mode 4 & $\begin{array}{l}\text { In this case, the associated battery arrived to the limit and the demand power less than the injected power in the } \\
\text { associated section, here to avoid the black-out case the other sections who have a SOC more than 20, the batteries } \\
\text { sharing the power to cover the missing power to feeding the damaged section. }\end{array}$ \\
\hline
\end{tabular}




\section{SIMULATION RESULTS AND DISCUSSION}

In this section, the studied model was simulated in Matlab Simulink software, where the obtained results are presented and discussed to verify the serviceability and efficiency of the proposed system. The use of variable weather conditions figure 6 aims to test the viability of the system under such disturbance and their effects on the obtained results, in addition to the selected schedule of the subsections loads.

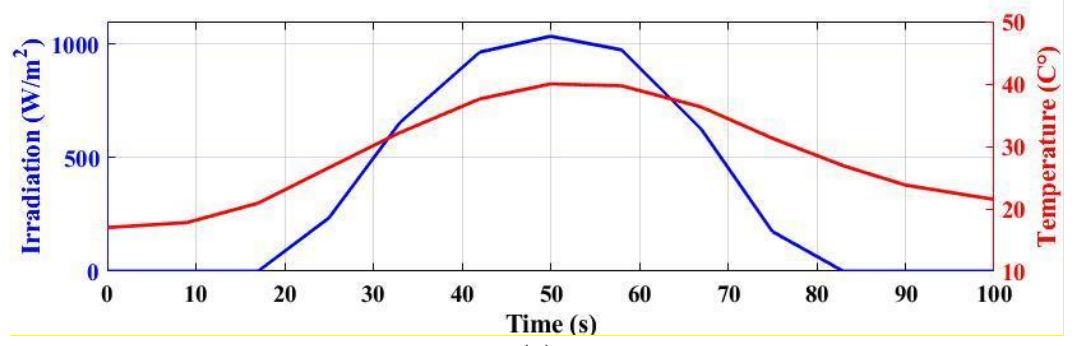

(a)

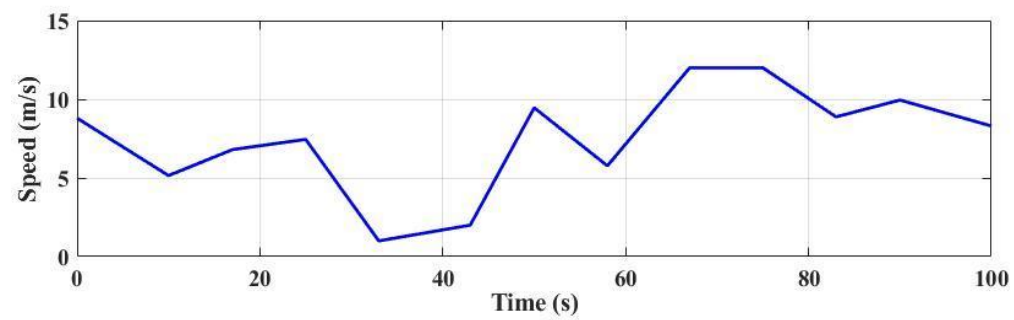

(b)

Figure 6. Variable profile of solar and wind solar parameters:

(a) The variation of irradiation and temperature of PV source. (b) The wind speed profile of WT.

Concerning the irradiation and temperature saw in figure (6-a), the day and the night profile has been represented. About the wind speed figure (6-b), we focused on three regimes from wind speed: rated speed mode, week speed mode where the WT is turned off and the third mode where the WT power is not optimal. Regarding the power profile demand, we represent the power profile similar to reality. The power demand was greater in the middle of the day especially in summer, where the power demand exceeds the assigned amount as in figure (8-b). Exactly, the rated power of this load section is $50 \mathrm{Kwp}$ and reached 70 Kwp to examine the reaction of the system and the effectiveness of the management decisions in such cases.

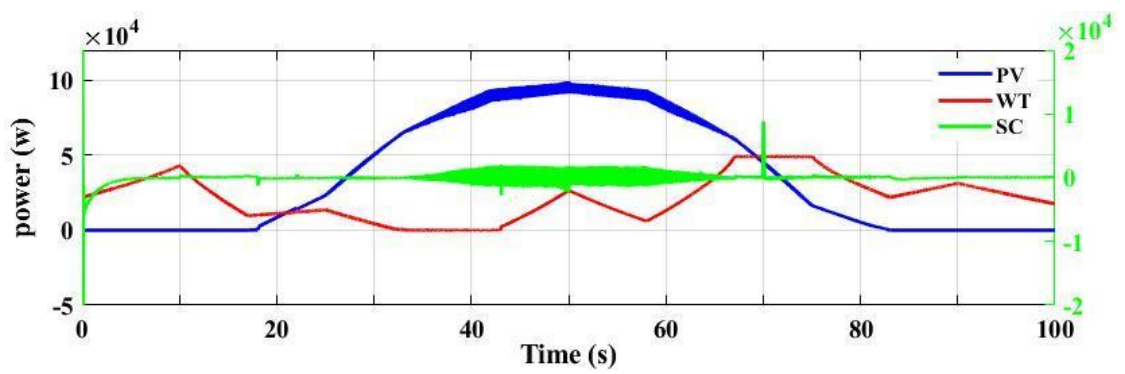

Figure 7. Power balance of the DERs (PV, WT) and SC.

Figure 7 shows the profile of the generated energy of the DERs and the SC. The PV source intervened during sunny hours between (17-83) s, where its maximum generated power was about $100 \mathrm{~kW}$ approximately at $50 \mathrm{~s}$ in the middle of the day. The rated output power of WT at rated wind speed $10 \mathrm{~m} / \mathrm{s}$ is $50 \mathrm{Kwp}$ as seen in the period from (67-75) s. Thus, the generated powers of the DERs are interruptible due to the intermittent nature of the used renewables as seen between (33-43) s where the wind speed was less than the cut-in speed. The big advantage of the supercapacitor SC is to generate/absorb fast current spikes to the 
load during transient regimes due to its high power density in addition to maintain the bus voltage within its specified limits. In addition, the fast response time of the SC during sudden cases can solve the disadvantage of the battery because of its slow dynamic and response time as seen in $70 \mathrm{~s}$.

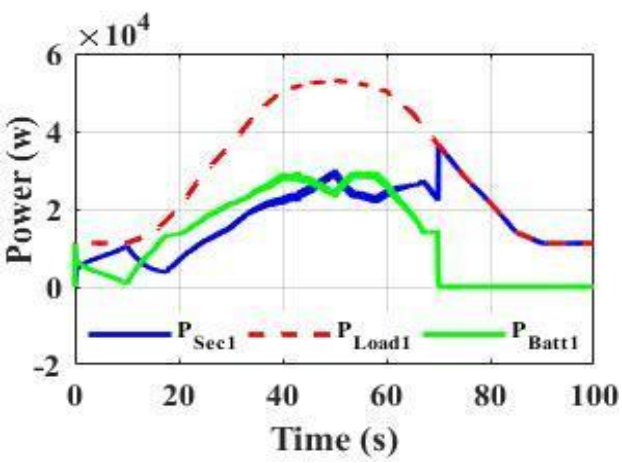

(a)

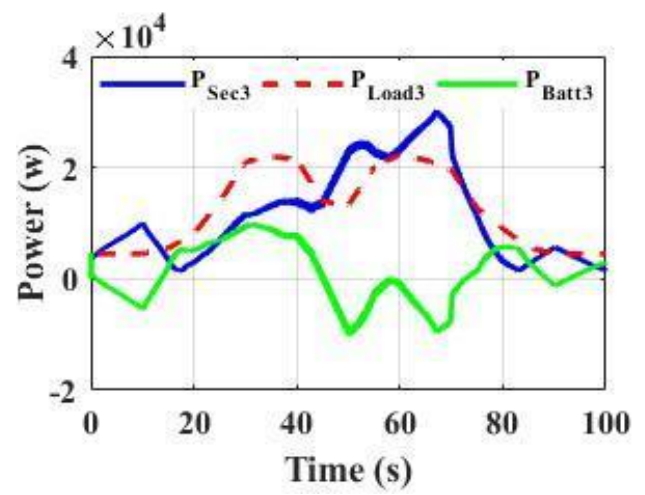

(c)

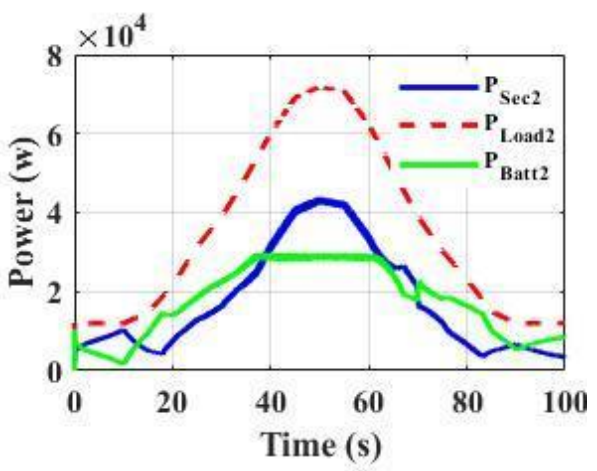

(b)

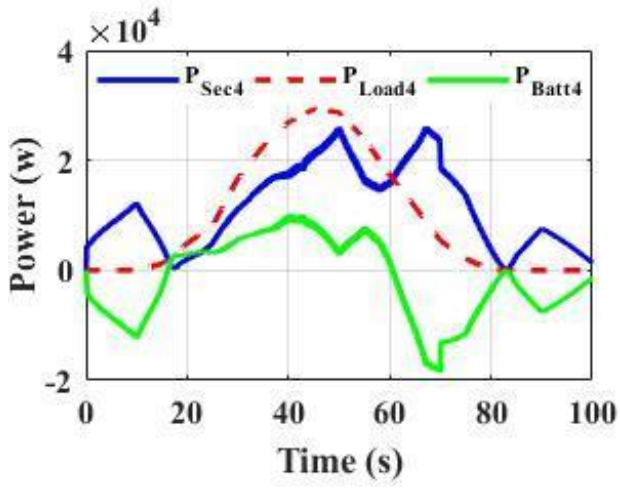

(d)

Figure 8. The power balance of the four subsystems: (a) First section, (b) Second section, (c) Third section and (d) Fourth section.

Figure 8 illustrates the power balance of the subsystems of the DC-MG, where the local load demands are plotted with its battery energy and the absorbed/generated power from/ to the common DC bus of the DC-MG. As viewed in each subsystem, the local load was supplied firstly by the renewable energy of the centralized power plant, while the local batteries intervene to cope with the energy mismatch between the load and the renewable energy. Exactly, the charge/discharge of the local batteries is controlled by the cascade-control-loop based on the variation of the common bus voltage to generate the reference current to the appropriate battery. During night hours, the wind turbine is the assigned resource to supply the load, while the permanent exceeded and/or lacked power is absorbed and/or generated by the local batteries and by the supercapacitor to cope with fast current spikes. If the centralized renewable energy does not much the total load demand of the whole system, the local batteries discharge following their state of charge, either to supply its local load or to share energy to the common DC bus with the other subsystems.

Thus, the global share energy between the DERs and the storage devices are controlled regarding the variation of the voltage of the common DC link. During the period (17-50) s, the PV power increase to its maximum peak, while the wind source provides its low powers. In this period, the fourth sub-sections are supplied via the available renewable energy and the batteries cover the missing power. For the third subsection, in the half-day, the power demand decreases temporarily so the correspondent unit storage absorbs the excess power. In the third period, from the half-day to the sunset (50-83) s, the PV power starts decreasing, the available wind power achieved its rated during (67-75) s, where the wind speed was $12 \mathrm{~m} / \mathrm{s}$ as represented in figure (6-b). In this period, the SOC of batteries were in the range (30-90), so batteries were charged/discharge to cover the load power demand and assure the DC-bus voltage following the reference value $400 \mathrm{~V}$. 
In the night period (83-100) s, the three sub-loads have a minimum power consumption for lighting and other small applications, while the fourth sub-loads which represent the agriculture application, do not consume any power. In this period, the available renewable sources are the WT in parallel with the local batteries. Exactly at (70) s, the battery of the first sub-system was disconnected out from the system caused by either if its SOC becomes less the $30 \%$ or due to an electrical fault as illustrated in Figure (8-a). Because of this problem, the centralized unit via renewable resources supplies the load of this sub-system completely, while the local batteries at the other sub-systems intervene to supply their local loads. Hence, the batteries are more stressed during this period, where the bus voltage is affected by a fast overshoot in addition to affecting the total stability of the DC-MG, where the DERs, the supercapacitor and batteries cope with the needed energy to mitigate the bus variations and provide the lacked energy to the appropriate load.

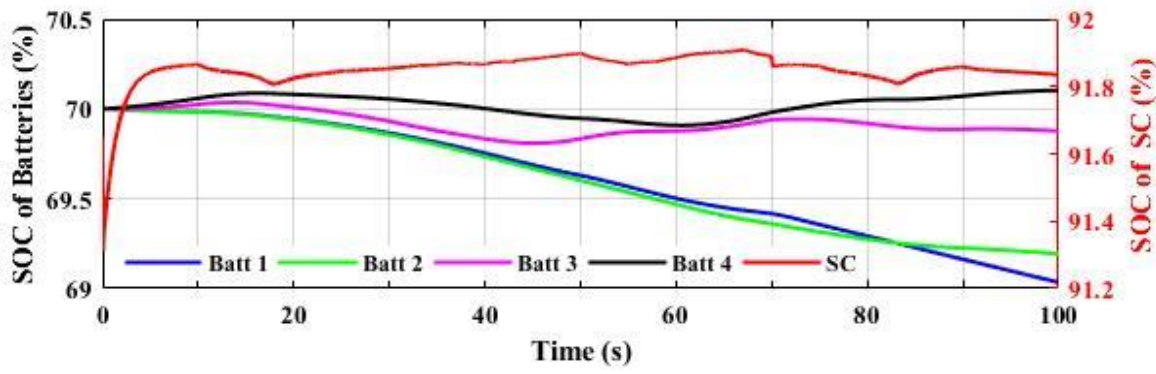

Figure 9. Batteries and SC state of charge.

Figure 9 represents the SOC of batteries of each sub-section and the SC. As can be observed, the SOC reflects the used energy of the storage devices during the power balance profile. The batteries are discharging especially at the half day when the demand power be greater, but where the demand load power be less the power generated the batteries are charging (the third and the fourth sub-sections), the first and second batteries are discharging at all time because of the demand power greater than the generated power. At night and after 70s the state of batteries be almost stable because the load demand power will be lower excepting the first sub-section, the batteries be off-line, and the continuation of the discharging batteries we explain it by the internal resistance.

The SC has a big role in the beginning as seen and in the transient periods because it delivers high power with very fast response time to ensure the stability of the dc-bus.

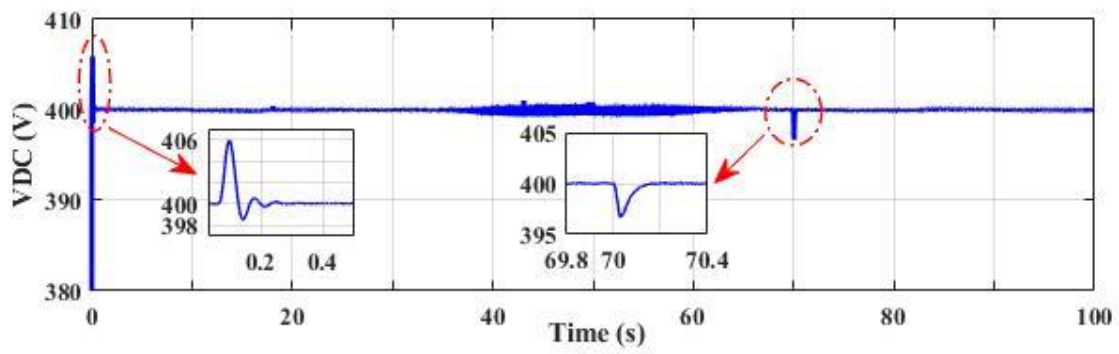

Figure 10. DC-bus voltage of the DC-MG.

Figure 10 represents the bus voltage of the DC-MG system with a reference value of $400 \mathrm{~V}$. The variation of the common bus voltage of the system indicates the amount of the available energy in the DCMG and consequently reflects its total stability. The bus voltage has a fast response time (about $0.27 \mathrm{~s}$ ) and small overshoot (about $6 \mathrm{~V}$ ). During the fast change in the generated powers of the renewable sources because of the unpredicted weather conditions, the supercapacitor intervenes firstly to cops with transient spikes to be followed by the local batteries either to charge or to discharge to meet the power difference between loads and DERs. The observed drops in the bus voltage are due to the fast reactions of the 
supercapacitor regarding the fast change in the available power at the common DC link, which is connected directly to the dc bus.

In general, the voltage of the common DC link was nearly constant around its reference with a minimum of $399 \mathrm{~V}$ and a maximum of $406 \mathrm{~V}$.

\section{CONCLUSION}

In this work, a proposed DC-MG is studied and presented as a solution for island villages and communities at the south of Algeria. Thus, the proposed system is controlled via cascade-control-loops to regulate the common bus voltage and planning the charge-discharge of the local batteries of each subsystem. Hence, an energy management policy EMP is developed to manage the shared energy inside the whole remote DC-MG including renewable energies DERs, HESS and variable AC/DC loads. Among controllers, MPPT is used to extract the maximum power of the renewable sources PV and wind. The selected semiactive topology for Batteries/SC has its advantages and disadvantages based on the proposed system, where the main objective is to mitigate the variations of the common DC link in addition to supply the fast current spikes to protect the chemical batteries because of their slow dynamic. From the obtained simulation results, the importance of the HESS with the renewable DERs is well shown in the presented power balance profiles. The proposed EMP is tested under normal, critical and emergency cases to generate the appropriate signal commands PWM to the power converters as seen in the case of the sudden absence of the battery at the first subsystem. Exactly, the whole DC-MG has proved its serviceability, efficiency and reliability during the entire applied disturbance such as variable weather conditions and unexpected faults that can occur in the network element and components.

\section{ACKNOWLEDGEMENTS}

Authors acknowledge the financial support of the General Direction of Scientific Research and Technological Development, DGRSDT through the PRFU Project ( ${ }^{\circ}$ A01L07UN080120120180007).

\section{REFERENCES}

[1] Dabbaghjamanesh, Morteza, Kavousifard, Abdollah, Mehraeen, Shahab, et al., "Sensitivity Analysis of Renewable Energy Integration on Stochastic Energy Management of Automated Reconfigurable Hybrid AC-DC Microgrid Considering DLR Security Constraint," IEEE Transactions on Industrial Informatics, 2019.

[2] YU, Yue et Wada, Keiji., "Simulation Study of Power Management for a Highly Reliable Distribution System using a Triple Active Bridge Converter in a DC Microgrid," Energies, vol. 11, no. 11, pp. 3178, 2018.

[3] H. Oussama, A. Othmane, C. Abdeselem , H. Mohammed Amine, "Wind turbine generator based on PMSG connected to DC microgrid system," International Journal of Control, Energy and Electrical Engineering, vol. 7, pp. 40-43, 2019.

[4] Ghanbari, Niloofar \& Mobarrez, Maziar \& Madadi, Mehrnaz \& Bhattacharya, Subhashish, "Comprehensive Cost Comparison and Analysis of Building-Scale Solar DC and AC Microgrid," 2019.

[5] Han, Ying, Chen, Weirong, et LI, Qi, "Modeling, control, and energy management for DC microgrid. In: Smart Power Distribution Systems," Academic Press. pp. 69-90, 2019.

[6] Bonkile, Mayur P. et Ramadesigan, Venkatasailanathan., "Power management control strategy using physics-based battery models in standalone PV-battery hybrid systems," Journal of Energy Storage, vol. 23, pp. 258-268, 2019.

[7] HU, Jiefeng, Shan, Yinghao, Xu, Yinliang, et al., "A coordinated control of hybrid ac/dc microgrids with PV-windbattery under variable generation and load conditions," International Journal of Electrical Power \& Energy Systems, vol. 104, pp. 583-592, 2019.

[8] Duman, A. Can et Güler, Önder, "Techno-economic analysis of off-grid PV/wind/fuel cell hybrid system combinations with a comparison of regularly and seasonally occupied households," Sustainable Cities and Society, vol. 42, pp. 107-126, 2018, 2017.

[9] Allaoua, Boumediene, Asnoune, Khadidja, et Mebarki, Brahim, "Energy management of PEM fuel cell/supercapacitor hybrid power sources for an electric vehicle," International journal of hydrogen energy, vol. 42, no 33, pp. 21158-21166, 2017.

[10] Tabatabaei, Naser Mahdavi, Kabalci, Ersan, et Bizon, Nicu, "Overview of Microgrid. In: Microgrid Architectures, Control and Protection Methods," Springer, Cham. pp. 3-19, 2020.

[11] Jing, Wenlong, Lai, Chean Hung, Wong, Shung Hui Wallace, et al., "Battery-supercapacitor hybrid energy storage system in standalone DC microgrids: areview," IET Renewable Power Generation, vol. 11, no 4, pp. 461-469, 2016.

[12] Kumar, Jaynendra, Agarwal, Anshul, et Agarwal, "Vineeta. A review on overall control of DC microgrids," Journal of Energy Storage, vol. 21, pp. 113-138, 2019.

[13] Hussain A. Attia, "High performance PV system based on artificial neural network MPPT with PI controller for direct current water pump applications", International Journal of Power Electronics and Drive Systems (IJPEDS), vol. 10, no. 3, pp. 1329-1338, 2019. 
[14] Ed-dahmani Chafik, Mahmoudi Hassane, Bakouri Anass, and El Azzaoui Marouane, "A New Adaptive AntiWindup Controller for Wind Energy Conversion System Based on PMSG”, vol. 9, no. 3, pp. 1321-1329, 2018.

[15] Banguero, Edison, Correcher, Antonio, Pérez-navarro, Ángel, et al., "A review on battery charging and discharging control strategies: Application to renewable energy systems," Energies, vol. 11, no 4, pp. 1021, 2018.

[16] Yin, Changjie, Wu, Hongwei, Locment, Fabrice, et al., "Energy management of DC microgrid based on photovoltaic combined with diesel generator and supercapacitor," Energy conversion and management, vol. 132, pp. 14-27, 2017.

[17] A kamel, Ahmed, Rezk, Hegazy, Shehata, Nabila, et al., "Energy Management of a DC Microgrid Composed of Photovoltaic/Fuel Cell/Battery/Supercapacitor Systems,” Batteries, vol. 5, no 3, pp. 63, 2019.

[18] Soumeur M., Gasbaoui B., Abdelkhalek O., Hartani M., Hafsi O., "Energy Management for a Hybrid Fuel cell/SC for Four-Wheel Drive Electric Vehicle," in Electrotehnica, Electronica, Automatica (EEA), vol. 67, no. 3, pp. 58-64, 2019.

[19] Moreno-valenzuela, Javier et García-alarcón, Octavio, "On control of a boost DC-DC power converter under constrained input," Complexity, 2017.

[20] Ravi, Deepak, Reddy, Bandi Mallikarjuna, Shimi, S. L., et al., "Bidirectional dc to dc Converters: An Overview of Various Topologies, Switching Schemes and Control Techniques," International Journal of Engineering and Technology, vol. 7, no 4, pp. 5, 2018.

[21] Soumeur, Mohammed Amine, Brahim Gasbaoui, Othmane Abdelkhalek, Jamel Ghouili, Tofik Toumi, and Abdeselem Chakar. "Comparative study of energy management strategies for hybrid proton exchange membrane fuel cell four wheel drive electric vehicle," Journal of Power Sources, vol. 462, 2020.

[22] Hartani M A, Hamouda M, Abdelkhalek O, Hafsi O, "Management of MPPT Technics and Energy Storage on Renewable Hybrid Power Systems", in Electrotehnica, Electronica, Automatica (EEA), vol. 67, no. 3, pp. 22-36, 2019.

[23] O. Zebraoui, M. Bouzi, "Improved MPPT controls for a standalone PV/wind/battery hybrid energy system", International Journal of Power Electronics and Drive Systems (IJPEDS), vol. 11, no. 2, pp. 988-1001, 2020.

[24] Zammit, Daniel, Staines, C. Spiteri, Micallef, Alexander, et al., "MPPT with current control for a PMSG small wind turbine in a grid-connected DC microgrid. In: Research and innovation on wind energy on exploitation in urban environment colloquium," Springer, Cham, pp. 205-219, 2017.

[25] Mousa, Hossam HH, Youssef, Abdel-Raheem, et Mohamed, Essam EM., "Variable step size P\&O MPPT algorithm for optimal power extraction of multi-phase PMSG based wind generation system," International Journal of Electrical Power \& Energy Systems, vol. 108, pp. 218-231, 2019. 